\title{
DỨBin
}

Technological University Dublin

ARROW@TU Dublin

\section{Informing quality in emergency care: understanding patient experiences}

\author{
Esmat Swallmeh \\ Technological University Dublin \\ Vivienne Byers \\ Technological University Dublin, vivienne.byers@tudublin.ie \\ Amr Arisha \\ Technological University Dublin
}

Follow this and additional works at: https://arrow.tudublin.ie/buschmanart

Part of the Business Administration, Management, and Operations Commons, and the Quality Improvement Commons

\section{Recommended Citation}

Swallmeh E, Byers V, Arisha A. Informing quality in emergency care: understanding patient experiences. Int J Health Care Qual Assur. 2018 Aug 13;31(7):704-717. doi: 10.1108/IJHCQA-03-2017-0052. PMID: 30354881.

This Article is brought to you for free and open access by the School of Management at ARROW@TU Dublin. It has been accepted for inclusion in Articles by an authorized administrator of ARROW@TU Dublin. For more information, please contact arrow.admin@tudublin.ie, aisling.coyne@tudublin.ie,gerard.connolly@tudublin.ie.

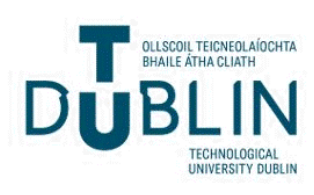


IJHCQA

31,7

\section{4}

Received 22 March 2017 Revised 27 August 2017 Accepted 9 November 2017

\section{Informing quality in emergency care: understanding patient experiences}

\author{
Esmat Swallmeh \\ Faculty of Business, Dublin Institute of Technology, Dublin, Ireland, and \\ Vivienne Byers and Amr Arisha \\ Dublin Institute of Technology (DIT), Dublin, Ireland
}

\begin{abstract}
Purpose - Assessing performance and quality in healthcare organisations is moving from focussing solely on clinical care measurement to considering the patient experience as critical. Much patient experience research is quantitative and survey based. The purpose of this paper is to report a qualitative study gathering in-depth data in an emergency department (ED).

Design/methodology/approach - The authors used empirical data from seven focus groups to understand patient experience as participants progressed through a major teaching hospital in an Ireland ED. A convenience sampling technique was used, and 42 participants were invited to share their perceptions and outline key factors affecting their journey. A role-playing exercise was used to develop improvement themes. Data were analysed using thematic analysis and data analysis software (NVivo 10).

Findings - Capturing ED patient experience increases our understanding and process impact on the patient journey. Factors identified include information, access, assurance, responsiveness and empathy, reliability and tangibles such as surroundings, food and seating.

Research limitations/implications - Owing to the ED patient's emergency nature, participants were recruited if triaged at levels 3-5 (Manchester Triage System). The study explored patients' immediate rather than post hoc experiences where recollections may change over time.

Originality/value - To the authors' knowledge, no study has examined in-depth, ED patient experience in Ireland using qualitative interviewing, obtaining critical process insights as it occurs. The potential to inform patient process improvements in Irish EDs is significant.
\end{abstract}

Keywords Patient satisfaction, Patient experience, Focus group, Emergency department

Paper type Research paper

\section{Introduction}

Securing greater patient and public engagement in healthcare has been a priority across OECD health systems for some decades. It is important that patients, health professionals, policy-makers and the public are involved to meet wider National Health Service, hospital and patient needs (Byers et al., 2017). Existing quality frameworks do not cover all care aspects that patients identify as relevant and important (Locock et al., 2014). The emergency department (ED) is critical as a first call for patients in the healthcare service delivery and is subject to the greatest public and media scrutiny (Gordon et al., 2010). Ireland EDs have been identified as needing significant reform. Overcrowding has been declared an emergency nationally, exacerbated by high patient demand, bed and staff shortages (Swallmeh et al., 2014). These demands correspond with dramatic cuts to infrastructure. In December 2014, an ED Task Force was convened to focus on the deteriorating ED performance in the Irish health system (Health Service Executive (HSE), 2015). The Irish Health Information and Quality Authority $(2012,2014)$ also released reports expressing concerns about ED patient safety. Recent statistics indicate increasing patient numbers waiting to access treatment, remaining on trollies and chairs owing to limited facilities (HSE, 2015; Irish Nurses and Midwives Organisation (INMO), 2017). The Irish Nurses and Midwives Organisation counts these additional patients above the stated complement and describes hospital overcrowding over recent years. Their analysis recorded 7,890 patients
International Journal of Health Care Quality Assurance pp. $704-717$

(c) Emerald Publishing Limite 0952-6862

DOI 10.1108/IJHCQA-03-2017-0052 Vol. 31 No. 7,2018

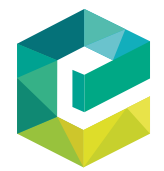


on trolleys in December 2016 awaiting admission for in-patient treatment, representing a 29 per cent increase compared to December 2015 (INMO, 2017). ED nurses have expressed frustration about the working environment and conditions for their patients and continue to involve media and other actions in protest about this deteriorating situation (INMO, 2017). In this context, we seek to address a significant research gap, namely, no in-depth studies

specifically examining ED patient experiences in Ireland from a qualitative perspective.

\section{Quality in healthcare: patient satisfaction vs patient experience}

Patient satisfaction and experience refer to measuring healthcare quality and survey instruments. To examine these concepts and their relationship to healthcare quality, it is important to differentiate between patient satisfaction and patient experience as the terms are not synonymous. Healthcare policy-makers, managers and professionals are increasingly aware of patient satisfaction's importance for both cost efficiency and quality (Epstein et al., 2010; Yarris et al., 2012). Patient satisfaction is an important service quality aspect, including structure and delivery, continuity and outcomes, and applying patient-centred care (Lally et al., 2013). Patient satisfaction can be defined as an emotion or attitude related to healthcare experience or as a judgment about whether expectations were met (Bloom, 2002). Patient satisfaction is influenced by varying standards, expectations, patient disposition, time since care and previous experience. Ensuring that patient responses in surveys act as a reliable satisfaction indicator. However, high satisfaction rates can indicate either high quality care or low expectations (Jenkinson et al., 2002; Fenton et al., 2012). Salisbury et al. (2010) advise that it is best to ask patients to report their experience rather than use satisfaction ratings to assess healthcare performance. Thus, it is important to differentiate between patient satisfaction and patient experience surveys. The latter use questions that relate to actual hospital experiences, which aim to avoid value judgments and expectation effects. Jenkinson $e t$ al. (2002) outline the core dimensions that patients identify as valuable about their healthcare experience, including information and communications with staff, continuity and coordination, physical comfort, emotional support, family and friend involvement and overall impression. Capturing patient experience is a key health services evaluation (Garratt et al., 2008). The patient perspective can be explored in depth and used as an incentive to improve service quality (Nijman et al., 2012). This understanding can develop healthcare initiatives that improve patient outcomes (Doyle et al., 2013). According to Sofaer and Firminger (2005), it can also improve overall healthcare system efficiency.

\section{Assessing patient experience}

In the ED, collecting patient-centred quality metrics remains preliminary, although patient preferences and perspectives are essential to healthcare delivery (Kilaru et al., 2016; Bardach et al., 2016). While studies measure patient experience, few report the exact approaches used. Information about instrument reliability and validity is often limited (de Silva, 2013). It is unclear whether current tools measuring patient-centred care or patient experience in healthcare reflects what is important to patients (Bardach et al., 2016). Many studies lack patient input, underutilising a potential resource by ignoring patients' unique insights into hospital service quality (Beattie et al., 2014). Care quality that affects patients' experience is distinctive and has multidimensional constructs that vary across different contexts. Surveys often cannot encompass that breadth and depth (Karassavidou et al., 2009; Rashid and Jusoff, 2009). Rapid changes to healthcare environments mean definitions may change over time (Wolf et al., 2014). Thus, healthcare providers must first understand the factors affecting patient experience from patients themselves, before they develop valid and reliable tools to measure those experiences. Patient experience research in the ED is dominated by quantitative measurements and little qualitative research (Gordon et al., 2010). 
IJHCQA

31,7

706

Recent studies utilising qualitative methods have thematically analysed online feedback data from websites such as Yelp (Kilaru et al., 2016) or older archival material (Locock et al., 2014). Gaps in measuring patient experience and particularly in the ED can be best met by exploring patient perspectives and experiences from a qualitative perspective. Our contribution, therefore, is a study carried out in the ED to enquire from patients about their experience whilst they progressed through the system - unique in an Irish and unusual in an international context.

Surveying patient experience identifies service improvement, an activity that requires specific data about what happened, not just data on whether patients were satisfied with what happened. Thus, patient experience surveys ask patients questions about what occurred during their healthcare experience (Wong et al., 2012). Examples include: "When you had important questions to ask a doctor, did you get answers you could understand"? The response choices include "Yes always", "Yes, sometimes", "No" and "I have no need to ask" (Jenkinson et al., 2002, p. 354). These questions can elicit responses that provide information identifying where in the process problems may reside and what can be done to improve patient care.

\section{Methodology}

We employed a focus group study among a convenience sample attending an Irish ED. The study was carried out in a major Dublin academic teaching hospital. Staff in the study hospital are under pressure to deal with changes to ED service configuration in the wider hospital group and to maintain adult emergency services capacity to cope with a growing and ageing catchment population. The hospital has 562 beds and treats over 410,000 patients per year. Approximately 83,400 patients attended the ED in 2016, a 5,500-patient increase on the previous year. Our study uniquely set out to explore ED patient experience in real time. The method chosen was focus group meeting defined as a technique to collect data through group interaction on a topic determined by the researcher (Morgan, 1996). This method, according to Kitzinger (1995), has distinct advantages for those researching healthcare; i.e., focus groups do not discriminate against people who cannot read or write, and they encourage participation from people reluctant to be interviewed on their own or who feel they have nothing to say. These focus groups did not interfere with care delivery; i.e., they were carried out as patients were waiting during the care delivery process.

\section{Informed consent and patient instruction}

Two weeks prior to the focus groups, a meeting was held with ED managers and staff to explain the focus group's purpose and the participant recruitment strategy. Staff were supportive and involved in the process. This approach was facilitated by several hospital wide patient experience initiatives that had gained staff trust. Cooperation was established with the triage nurse to select an eligible sample for study. After completing the triage process, the triage nurse gave patients (meeting the inclusion criteria) study packs, which included a participant information leaflet and consent form. Patients who expressed interest in participating in the focus group meetings were asked to sign and submit the consent form. Posters were displayed in the patients' waiting room, informing ED patients about the study. Focus group meetings were held in the adjacent ED conference room.

\section{Participants}

A nonprobability convenience sampling research strategy provided access to ED attendees, which facilitates access to core interviewees to establish their perspectives through rich qualitative information. Though acknowledging accompanying family members, the focus was on the patients' perspectives. Although generalising our findings to the wider ED 
population is not possible with convenience sampling, by employing this approach, the study provides initial patient opinions to guide further research in the area. This study is in a wider project that aims to integrate constraints theory, lean processes and simulation modelling together, and informing a patient survey instrument to improve process throughputs and hence improve patient experience. In total, 42 patients participated in seven focus groups. The requirements for participation included ED patients 18 years old, triaged at levels 3-5 (Manchester Triage System (MTS) (Mackway-Jones et al., 2014), not in pain and fluent in English. The MTS is a commonly used triage system in Europe. It enables nurses to assign a clinical priority to patients, based on presenting signs and symptoms, without making any assumption about the underlying diagnosis. The MTS allocates patients to one from five urgency categories, which determine the maximum time to first contact with a physician (Zachariasse et al., 2017). These categories range from "immediate" coded as 1 to "non-urgent" coded as 5 . Table I represents the patients' demographic characteristics and shows that most were female (69 per cent) and self-referred to the ED (71 per cent).

\section{Patient experience focus groups}

Focus group meetings were run by an experienced independent moderator, who had no affiliation to the ED. The first author attended to take field notes and recordings. The focus group meetings were conducted between November 2013 and February 2014, each session lasting $40-50 \mathrm{~min}$. To put participants at ease, refreshments were provided, and they were engaged in a general discussion (Dilshad and Latif, 2013). The focus group meetings were conducted at various times of the day and night. Each followed a set protocol beginning with introducing the research team to the participants, who were informed that the study's main objective was to explore the factors that affected their ED experience. The moderator encouraged all participants to engage in the group process and guarded against the "dominant voice". The moderator used reflective probes to encourage participants to clarify their statements and elaborate their remarks (Gill et al., 2008).

\section{Ethical considerations}

There is an ethical mandate for patient participation and engagement in health services research, which can improve clinical practice (Liamputtong, 2011).

\begin{tabular}{lc}
\hline Participants & $n(\%)$ \\
\hline Gender & $29(69 \%)$ \\
Female & $13(31 \%)$ \\
Male & $1(2 \%)$ \\
Age & $6(14 \%)$ \\
$18-24$ & $18(43 \%)$ \\
$25-34$ & $13(31 \%)$ \\
$35-50$ & $4(10 \%)$ \\
$51-65$ & \\
$>65$ & $2(4 \%)$ \\
Education & $17(41 \%)$ \\
Primary & $23(55 \%)$ \\
Secondary & \\
Higher & \\
Referral mode & $30(71 \%)$ \\
Self & $12(29 \%)$ \\
GP & Demographic data \\
\hline
\end{tabular}

Informing quality in emergency care 
IJHCQA

31,7
Ethical approval was granted by the hospital's ethics board. Full information was given to participants, which explained confidentiality, their autonomy and their right to withdraw at any time.

\section{Data analysis}

All focus group transcripts and field notes were analysed using a thematic analysis method to identify, examine and report data patterns (Braun and Clarke 2006). Initially, a codebook was established using data obtained from the first focus group meeting. As the analysis proceeded, an independent reviewer expanded the codebook by reviewing each transcript as an analytical unit. Emerging themes were grouped under headings. A qualitative data analysis software programme (NVivo ${ }^{\mathrm{TM}}$ 10, QSR International, 2012) was used to facilitate data management and analysis, which managed and organised data, and facilitated access to conceptual and theoretical knowledge (Bazeley and Jackson, 2013). To maintain research quality, personal values were not allowed to influence data collection and analysis, which was achieved by the authors involved in the study examining the data and cross-checking the thematic analysis. Focus group participants identified 19 common factors that affected their experience during their ED visit. These factors were grouped under six themes, which included: reliability, information, assurance, responsiveness, tangibles and empathy (depicted in the following list "Themes and subthemes emerging from focus group meetings").

Themes and subthemes emerging from focus group meetings

Theme 1: Reliability

Subthemes:

(1) Waiting time management:

- triage

- seen by a doctor

- medical/surgical consult

- transfer to ward

(2) Privacy

(3) Access

\section{Theme 2: Information}

Subthemes:

(1) Expect to be updated during their process

(2) Accurate time estimate to be seen by ED doctor

(3) Explanation of unexpected delays

(4) Reasons behind decisions related to treatment

(5) How to take prescribed medication and potential side effects

(6) Need to be familiarised with ED and triage processes

Theme 3: Assurance

Subthemes:

(1) Staff to have necessary knowledge

(2) Friendly healthcare staff

(3) Safety

(4) Hospital having modern equipment 
Theme 4: Responsiveness

Informing

Subthemes:

(1) Staff to have time to answer questions

(2) Responding to complaints instantly and solving the issue immediately

Theme 5: Tangibles

Subthemes:

(1) Availability of healthy food

(2) Need for clean and warm waiting room

(3) Comfortable seating

Theme 6: Empathy

Subthemes:

(1) To be treated with respect and dignity

(2) Staff to be attentive to the specific needs of different patients

\section{Results}

\section{Theme 1: reliability}

Waiting time. All participants reported that waiting time had an important impact on their ED experience. All expressed frustration at their long waits. Participants saw triage as the first stage in their treatment journey and expected to be seen by a triage nurse in less than $5 \mathrm{~min}$. While some participants expected to be seen by a doctor within $45 \mathrm{~min}$, others expected to be seen within a maximum two-hour window:

I am waiting over four hours; do you believe that no one checked on me (FG3: Participant 1).

At the same time, I don't like to spend all day waiting for my turn to be treated (FG4: Participant 1).

Once called to the treatment room, participants expected to be examined by the ED doctor without delay and have their investigation completed. Many participants also expressed frustration about waiting for a long time to receive their investigation results:

If bloods have been taken from you, sometimes it takes two hours to be informed about the results (FG3: Participant 2).

Another significant factor during their ED journey was waiting for medical or surgical consultations. Several participants with previous ED experience articulated their annoyance at having to wait for review until the surgeons were finished their work:

$[\ldots]$ the nurse told us that the results were ready, but the doctor was very busy in resuscitation and will talk to you when s/he has a chance (FG5: Participant 1).

Finally, participants expected to be discharged in a timely manner when treatment was finished, or, if admitted, to be transferred to a ward bed within $30-45 \mathrm{~min}$. All participants noted that communication alleviated the pressure and uncertainty when waiting. Many had different suggestions such as leaflets explaining the system or TV monitors with waiting times.

Privacy. Participants from three focus groups described privacy as a critical element during their ED visit. Participants expected privacy during all ED stages from registration until they left the unit. Participants expected to be treated as individuals, and expressed 
IJHCQA

31,7

710

difficulty in being left sitting in the waiting room in severe pain without having their privacy protected:

When you register, everyone can hear you. If you are in pain sitting in the waiting room, everyone is watching you. If you are on a trolley or chair inside, it is even worse, others will be passing by as if you didn't exist (FG4: Participant 2).

Access. Participants stressed the hospital's geographical location and easy access for critically ill patients. Safe and affordable parking on the site helped to reduce patient and family anxiety.

\section{Theme 2: information}

All participants said that information provided by staff was crucial and can be a valuable part of their ED experience. The degree to which waiting times affected participants was associated with the information that ED staff provided. Participants wanted to be updated frequently at all stages, including being given accurate estimates of how long they would have to wait to be seen by the ED doctor, reasons for unexpected delay, decisions regarding their treatment process, information about how to take prescribed medications and their possible side effects:

Why can't the triage nurse tell us roughly the expected time to see a doctor, and when there is a delay to let us know? (FG3: Participant 3).

Participants also discussed their unfamiliarity with the ED and triage process, and that information could overcome their anxieties. They expected the doctors to explain their condition and treatment plan in simple language:

Sometimes when the doctor speaks to you, maybe he thinks that he is speaking to a nurse or another doctor, because he uses some words that I don't understand (FG2: Participant 1).

Participants in two focus groups talked about considering leaving the ED without being treated as they were given no information about how long they could expect to wait for treatment. Additionally, members in three focus groups said that directional signage to guide patients to different ED departments was missing:

Because of the poor direction signs, people were lost when they were going to the shop or the canteen, also when going and coming back from X-ray (FG1: Participant 1).

\section{Theme 3: assurance}

Participants were anxious in the ED. Some were unsure of the process and some had listened to media reports and felt vulnerable owing to their health issues. They needed information and assurance:

It is good that when you are sick that you understand everything happening around you and why it is happening. Then you feel that everything is under control. Knowing who are the healthcare staff looking after you. What do they think about your condition, further tests to be done and how long you have to wait for these tests. If there is a delay in doing it, one of the staff needs to come back to us and tell us about the delay instead of disappearing and then you have to call any healthcare staff passing by to ask how long I have to wait (FG5: Participant 5).

Most participants expressed the expectation that healthcare staff should have the necessary medical knowledge to treat them safely and to answer their questions in a friendly way. Some participants also considered safety as an issue that needed to be addressed in the ED waiting room:

Sometimes we don't feel safe in the waiting room especially with drunk people and people who are taking drugs (FG1: Participant 2). 
Several participants stressed that hospitals should have enough modern equipment and qualified staff. They were concerned that the hospital had the proper equipment to help the doctor diagnose patient conditions accurately, especially if they were critical as there might only be a short window to carry out successful treatment.

\section{Theme 4: responsiveness}

Participants in five focus groups emphasised how the ED was constantly busy so that staff were unable to find enough time to communicate with them appropriately. They expected ED staff to respond to requests and to deal with their complaints instantly:

I know the ED is very busy and the staff are over loaded, but I think communication with the patients and updating their information is essential (FG2: Participant 2).

Participants discussed the slow response providing appropriate pain relief to patients in distress but were unaware that there may be medical reasons behind staff practices:

Even if you have pain, you have to ask for painkillers many times. A lady sitting in the waiting room looks dreadful from pain, she was given nothing (FG4: Participant 3).

\section{Theme 5: tangibles}

The physical factors that were suggested to ensure ED patients' comfort included seating, food, beverages, plug-points (to charge phones), Wi-Fi and heating. Many participants mentioned being able to purchase healthy food while they were waiting for prolonged periods:

The food available in the shop is only sandwiches and the canteen is very expensive. The food machine available has junk food and it is empty today. When we asked the staff, they said that they have no control of the machine and the company will come tomorrow to fill it up. The coffee machine is not working as well (FG1: Participant 3).

Also, they noted that the waiting room should be clean and warm and have enough comfortable seating.

\section{Theme 6: empathy}

Participants from four focus groups discussed ED's emotional impact. They felt vulnerable and fearful, and that they would lose their autonomy and independence. Participants felt strongly about being treated with respect and dignity. They also expected ED staff to be attentive to different patients' specific needs; for example, older patients who needed more responsive care.

\section{Improvements suggested by patients}

Based on identified themes, a role-playing exercise was conducted with all focus group participants to suggest improvements. Carefully designed role-play can substantially add to the focus group's value by increasing productive discussion (Bill and Olaison, 2009). Participants were asked to play ED staff roles and suggest improvements. Participants from all the focus groups discussed the patient's ED pathways and the need for urgent improvements so that patients could be seen more quickly. ED fast track is a designated area where lower acuity ED patients are seen rapidly (Hwang et al., 2015). Some participants suggested that senior ED doctors and nurses participate in the triage process to increase patient throughput and to improve ED turnover times, reduce patient waiting times and their frustration. Another strategy was to reduce the numbers attending the ED unnecessarily by improving local primary care services (mainly general practitioner (GP) services). Participants felt that GP clinics did not always have the appropriate equipment, 
IJHCQA 31,7

712 such as ECG and ultrasound. Some focus group participants also suggested an advisory phone-line or website on a 24-hour basis that would mitigate against unnecessary ED visits (Figure 1), which are already being used in the UK (NHS 24-hour support service).

\section{Discussion}

We aimed to understand patient experiences as participants progressed through a major Irish teaching hospital ED. Locock et al. (2014) note that many qualitative patient experience measures do not portray what is salient to the patient and they are not involved in their construction. There can be a gap between patient and healthcare provider views about what is important, and there have been limited attempts to explore this gap (Watt et al., 2005). Our findings contribute to previous research by identifying factors that are important to ED patients and their experience. Our unique contribution is engagement with patients in real time as they progress through an ED, rather than post hoc when recalled experiences may change over time. There is a risk that seeking answers when patients are at their most vulnerable during care and treatment can affect their perceptions. However, study participants were reflective and positive in the main about their experiences. They appreciated that ED teams are under pressure, which can impede staff delivering a more responsive service. They also recognised the wider health system's impact on ED processes. The factors we identified as important were like findings in previous studies and included reliability (Göransson and von Rosen, 2010), information (Kilaru et al., 2016; Ranney and Peimer, 2016), assurance (Bardach et al., 2016), responsiveness (Burström et al., 2013), tangibles (Coughlan and Corry, 2007; Naidu, 2009) and empathy (Gordon et al., 2010). Participants were at one in seeking therapeutic rapport from ED staff, in keeping with research looking at the beneficial relations and good communications for ED patients (Baillie, 2005). It is person-centred care that is core, which patients require to cope with their situation:

Actually, no one likes to come to ED without a reason. When we come [...] we have no choice except to be here. Therefore, we like to be treated with respect and dignity, and in an accepted time [...] People are very angry sitting in the waiting room for long hours without being informed or anyone to check on their condition (FG1: Participant 2).

In common with literature on the factors affecting ED patient satisfaction and experience, waiting times were paramount (Göransson and von Rosen, 2010; Burström et al., 2013). Although ED waiting times are not always associated with overall hospital satisfaction (Pines et al., 2008), previous literature links them with patients reporting lower ED satisfaction scores (Parker and Marco, 2014). Increased waiting times have been linked to

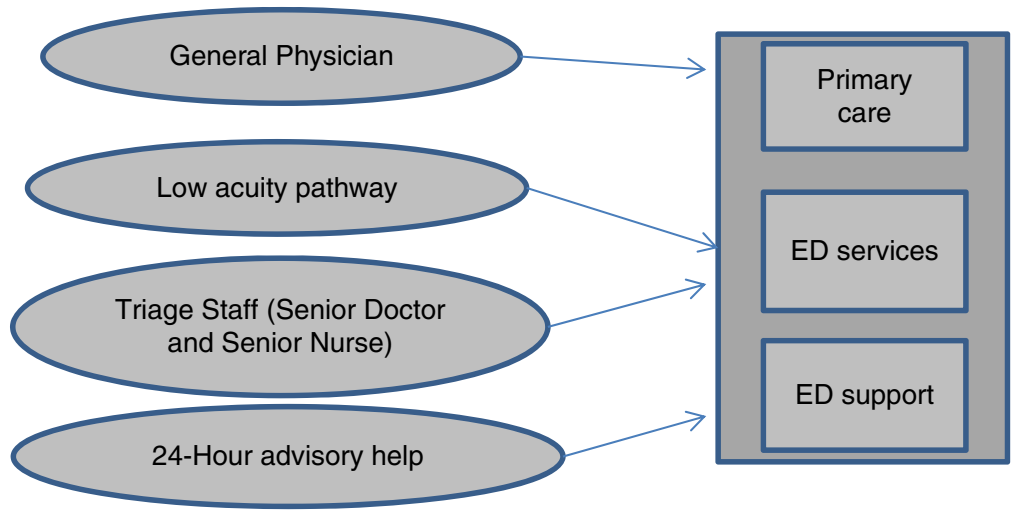

Figure 1.

Services suggested by patients to improve patient experience 
negative ED performance and to patients leaving without being seen (Forrestal et al., 2013). In one study, longer waiting times were linked to fewer patients (14 per cent) considering returning to the same ED (Health Services Research Centre ISQH, RCSI and Ipsos MORI Ireland, 2007).

While healthcare providers focus on clinical practice to achieve high quality care (Watt et al., 2005), patients place a high value on communication processes during their ED journey (Kilaru et al., 2016). Our findings concur with recent studies that thematically analysed patient feedback on social media (Yelp and Twitter), which indicate that waiting times can be proactively managed through communication (Kilaru et al., 2016; Ranney and Peimer, 2016; Perez-Carceles et al., 2010). Participants in our study emphasised that receiving updated information about their treatment and estimated wait times during the process were important. Keeping patients and their families fully informed is seen to be a key patient satisfaction determinant having more effect on patient perceptions than any other variable, even when waiting times are increasing (Johnson et al., 2012).

Participants in our study consider triage as the first stage and expect to be seen by a triage nurse promptly. A pertinent research study stressed the triage process and found that accelerating the process reduces the patients who might leave without being seen (Levsky et al., 2008). Patients expected to be seen by an ED doctor within two hours compared to six hours as recommended by the Irish Health Service Executive (2012). The 2017 national key performance indicators for ED performance include a 75 per cent target for all ED attendees to be discharged or admitted within six hours of registration and that less than 5 per cent of all ED patients at the ED will leave before completing treatment (Health Service Executive, 2017). One improvement strategy suggested by the patients in our study was to have a multidisciplinary triage team. Research found that this strategy helps to reduce the total patients leaving without being seen and improves waiting times (Richardson et al., 2004; Oredsson et al., 2011).

Our findings confirm that the ED environment is important for patient welfare (Atinga et al., 2011). We concur with previous research on the difficulty recruiting ED patients for research purposes owing to patients' frustrations with waiting times, minimal information regarding their treatment and stress (Kington and Short, 2010). Bardach et al. (2016) analysed online reviews by patients and identified themes that do not feature in patient experience surveys (HCAHPS) including financing, system-centred care and safety perceptions, which also emerged in our study.

In Ireland, an ED Task Force was set up in 2015 following a deterioration in ED performance (trolley waits) (HSE, 2015). It identified that EDs were at a critical juncture and identified several short- and longer-term strategies. One was to actively pursue patients' hospital experience and opinions through a formal platform, as patient involvement is a key Irish Hospital Redesign Programme (HSE, 2015). Our study identifies factors that patients see as important regarding their ED experience, which need to be considered seriously by healthcare managers and policy-makers as part of this programme and to contribute to the literature on understanding patient-centred care to improve healthcare systems. Although generalising our findings to the wider ED population is not possible with convenience sampling, our research approach provides front-line patient opinions to guide further research. These findings in common with other ED research indicate how patients value engagement and communication in their ED journey. Thus, informing and educating healthcare managers and ED staff that patient communication has implications for both Irish and other healthcare systems. Our data presented are part of a wider project, which aims to integrate constraints theory, lean processes and simulation modelling together to improve process throughputs and hence improve patient experience. Other research can help to understand the factors affecting healthcare service delivery from the families' and carers', and healthcare staff's view point. 
IJHCQA

31,7

\section{Conclusion}

Our study sought to identify the factors that affect ED patient experience from the patient's perspective. Healthcare leaders have increasingly acknowledged that patient experience is now a top priority (Wolf et al., 2014). Patient involvement in healthcare design and delivery is a crucial element and patient-centred care requires refocussing towards developing relationships between patients and their care providers; and providing an environment that supports development (Rathert et al., 2016). Our study reports focus group interviews to understand patient experience as they progressed through a Dublin teaching hospital's ED. Rather than relying on patient tick box surveys (Locock et al., 2014; Robert and Cornwell, 2013), focus groups allow patients to express their feelings about their own healthcare experiences in their own words. Our participants all considered waiting time and communication as key factors. Thus, our results confirm earlier patient experience survey research findings (Jenkinson et al., 2002). However, our research is unique in accessing patients' perceptions in "real-time" and reflecting their immediate concerns when asked about their experience, as they navigate the ED. Thus, our research confirms that patient experience research is valuable. Communication with and information gained from patients as they navigate an ED is not to be undervalued. This research approach is both underutilized and under-appreciated in emergency medicine. The data we present are the project's first phase, which is designed to improve patient experience.

\section{References}

Atinga, R.A., Abekah-Nkrumah, G. and Domfeh, K.A. (2011), "Managing healthcare quality in Ghana: a necessity of patient satisfaction", International Journal of Health Care Quality Assurance, Vol. 24 No. 7, pp. 548-563.

Baillie, L. (2005), "An exploration of nurse - patient relationships in accident and emergency", Accident and Emergency Nursing, Vol. 13 No. 1, pp. 9-14.

Bardach, N.S., Lyndon, A., Asteria-Peñaloza, R., Goldman, L.E., Lin, G.A. and Dudley, R.A. (2016), "From the closest observers of patient care: a thematic analysis of online narrative reviews of hospitals”, BMJ Quality \& Safety, Vol. 25 No. 11, pp. 889-897.

Bazeley, P. and Jackson, K. (2013), Qualitative Data Analysis with NVivo, 2nd ed., revised, Sage Publications Limited, Los Angeles, CA.

Beattie, M., Lauder, W., Atherton, I. and Murphy, D.J. (2014), "Instruments to measure patient experience of health care quality in hospitals: a systematic review protocol", Systematic Reviews, Vol. 3 No. 1, pp. 4-12, available at: https://doi.org/10.1186/2046-4053-3-4

Bill, F. and Olaison, L. (2009), "The indirect approach of semi-focused groups: expanding focus group research through role-playing", Qualitative Research in Organizations and Management: An International Journal, Vol. 4 No. 1, pp. 7-26.

Bloom, B.S. (2002), "Crossing the quality chasm: a new health system for the 21st century", The Journal of the American Medical Association, Vol. 287 No. 5, pp. 646-647.

Braun, V. and Clarke, V. (2006), "Using thematic analysis in psychology", Qualitative Research in Psychology, Vol. 3 No. 2, pp. 77-101.

Burström, L., Starrin, B., Engström, M.L. and Thulesius, H. (2013), "Waiting management at the emergency department - a grounded theory study", BMC Health Services Research, Vol. 13 No. 1, pp. 95-105, available at: https://doi.org/10.1186/1472-6963-13-95

Byers, V., Fahey, D., Mullins, C. and Roe, C. (2017), "The patient survey programme: transforming the patient experience in Irish healthcare", Administration, Vol. 65 No. 4, pp. $83-99$ (in press).

Coughlan, M. and Corry, M. (2007), "The experiences of patients and relatives/significant others of overcrowding in accident and emergency in Ireland: a qualitative descriptive study", Accident and Emergency Nursing, Vol. 15 No. 4, pp. 201-209.

de Silva, D. (2013), Measuring Patient Experience: Evidence Scan, Health Foundation, London. 
Dilshad, R.M. and Latif, M.I. (2013), "Focus group interview as a tool for qualitative research: an analysis", Pakistan Journal of Social Sciences, Vol. 33 No. 1, pp. 191-198.

Doyle, C., Lennox, L. and Bell, D. (2013), "A systematic review of evidence on the links between patient experience and clinical safety and effectiveness", BMJ Open, Vol. 3 No. 1, pp. 1-18.

Epstein, R.M., Fiscella, K., Lesser, C.S. and Stange, K.C. (2010), "Why the nation needs a policy push on patient-centered health care", Health Affairs, Vol. 29 No. 8, pp. 1489-1495.

Fenton, J.J., Jerant, A.F., Bertakis, K.D. and Franks, P. (2012), "The cost of satisfaction: a national study of patient satisfaction, health care utilization, expenditures, and mortality", Archives of Internal Medicine, Vol. 172 No. 5, pp. 405-411.

Forrestal, B., Hynes, T., Clarke-Moloney, M., Coyle, P., Boyle, E., Burke, P., Walsh, S.R., Quin, G. and Grace, P.A. (2013), "Patient satisfaction following emergency admission via a surgical assessment unit and an emergency department", Irish Journal of Medical Science, Vol. 182 No. 2, pp. 261-266.

Garratt, A., Solheim, E. and Danielsen, K. (2008), National and Cross-National Surveys of Patient Experiences: A Structured Review, Norwegian Knowledge Centre for Health Services, Oslo.

Gill, P., Stewart, K., Treasure, E. and Chadwick, B. (2008), "Methods of data collection in qualitative research: interviews and focus groups", British Dental Journal, Vol. 204 No. 6, pp. 291-295.

Göransson, K.E. and von Rosen, A. (2010), "Patient experience of the triage encounter in a Swedish emergency department", International Emergency Nursing, Vol. 18 No. 1, pp. 36-40.

Gordon, J., Sheppard, L.A. and Anaf, S. (2010), "The patient experience in the emergency department: a systematic synthesis of qualitative research", International Emergency Nursing, Vol. 18 No. 2, pp. 80-88.

Health Information and Quality Authority (2012), "Report of the investigation into the quality, safety and governance of the care provided by the Adelaide and Meath hospital, Dublin, incorporating the National 257 Children's Hospital (AMNCH) for patients who require acute admission", Health Information and Quality Authority, Dublin.

Health Information and Quality Authority (2014), "Report of the review of the governance arrangements as reflected in the safety, quality and standards of services at UL Hospitals", Health Information and Quality Authority, Dublin.

Health Services Research Centre ISQH, RCSI and Ipsos MORI Ireland (2007), "Health Service Executive emergency departments. Patient profiles, experiences and perceptions. Report of a national survey among people who attended during 2006”, HSE, Dublin.

Health Service Executive (2012), The National Emergency Medicine Programme: A Strategy to Improve Safety, Quality, Access and Value in Emergency Medicine in Ireland, Clinical Strategy and Programmes Directorate, HSE, Dublin.

Health Service Executive (HSE) (2015), Emergency Department Task Force, HSE, Dublin.

Health Service Executive (2017), KPI Metadata 2017, HSE, Dublin.

Hwang, C.E., Lipman, G.S. and Kane, M. (2015), "Effect of an emergency department fast track on Press-Ganey patient satisfaction scores", Western Journal of Emergency Medicine, Vol. 16 No. 1, pp. 34-38.

Irish Nurses and Midwives Organisation (INMO) (2017), "ED overcrowding crisis deepens with 541 admitted patients on trolleys", 13 December 2016, available at: www.inmo.ie/Home/Index/217/12815 (accessed March 2017).

Jenkinson, C., Coulter, A. and Bruster, S. (2002), "The picker patient experience questionnaire: development and validation using data from in-patient surveys in five countries", International Journal for Quality in Health Care, Vol. 14 No. 5, pp. 353-358.

Johnson, M.B., Castillo, E.M., Harley, J. and Guss, D.A. (2012), "Impact of patient and family communication in a pediatric emergency department on likelihood to recommend", Pediatric Emergency Care, Vol. 28 No. 3, pp. 243-246. 
IJHCQA 31,7
Karassavidou, E., Glaveli, N. and Papadopoulos, C.T. (2009), "Quality in NHS hospitals: no one knows better than patients", Measuring Business Excellence, Vol. 13 No. 1, pp. 34-46.

Kilaru, A.S., Meisel, Z.F., Paciotti, B., Ha, Y.P., Smith, R.J., Ranard, B.L. and Merchant, R.M. (2016), "What do patients say about emergency departments in online reviews? A qualitative study", BMJ Quality and Safety, Vol. 25 No. 1, pp. 14-24.

Kington, M. and Short, A.E. (2010), "What do consumers want to know in the emergency department?", International Journal of Nursing Practice, Vol. 16 No. 4, pp. 406-411.

Kitzinger, J. (1995), "Qualitative research. Introducing focus groups”, British Medical Journal, Vol. 311 No. 7000 , pp. 299-302.

Lally, J., Byrne, F., McGuire, E. and McDonald, C. (2013), "Patient satisfaction with psychiatric outpatient care in a university hospital setting", Irish Journal of Psychological Medicine, Vol. 30 No. 4, pp. 271-277.

Levsky, M.E., Young, S.E., Masullo, L.N., Miller, M.A. and Herold, T.J. (2008), "The effects of an accelerated triage and treatment protocol on left without being seen rates and wait times of urgent patients at a military emergency department", Military Medicine, Vol. 173 No. 10, pp. 999-1003.

Liamputtong, P. (2011), Focus Group Methodology: Principle and Practice, Sage, Los Angeles, CA.

Locock, L., Robert, G., Boaz, A., Vougioukalou, S., Shuldham, C., Fielden, J., Ziebland, S., Gager, M., Tollyfield, R. and Pearcey, J. (2014), "Testing accelerated experience-based co-design: a qualitative study of using a national archive of patient experience narrative interviews to promote rapid patient-centred service improvement", Health Service Delivery Research, Vol. 2 No. 4, pp. 1-13.

Mackway-Jones, K., Marsden, J. and Windle, J. (2014), Emergency Triage: Manchester Triage Group, 3rd ed., BMJ Publishing Group, London.

Morgan, D.L. (1996), "Focus groups", Annual Review of Sociology, Vol. 22 No. 1, pp. 129-152.

Naidu, A. (2009), "Factors affecting patient satisfaction and healthcare quality", International Journal of Health Care Quality Assurance, Vol. 22 No. 4, pp. 366-381.

Nijman, J.L., Sixma, H., van Triest, B., Keus, R.B. and Hendriks, M. (2012), "The quality of radiation care: the results of focus group interviews and concept mapping to explore the patient's perspective", Radiotherapy and Oncology, Vol. 102 No. 1, pp. 154-160.

Oredsson, S., Jonsson, H., Rognes, J., Lind, L., Göransson, K.E., Ehrenberg, A., Asplund, K., Castrén, M. and Farrohknia, N. (2011), "A systematic review of triage-related interventions to improve patient flow in emergency departments", Scandinavian Journal of Trauma, Resuscitation and Emergency Medicine, Vol. 19 No. 1, pp. 43-52, available at: https://doi.org/10.1186/1757-7241-19-43

Parker, B.T. and Marco, M.D. (2014), "Emergency department length of stay: accuracy of patient estimates", Western Journal of Emergency Medicine, Vol. 15 No. 2, pp. 170-175.

Perez-Carceles, M.D., Gironda, J.L., Osuna, E., Falcon, M. and Luna, A. (2010), "Is the right to information fulfilled in an emergency department? Patients' perceptions of the care provided", Journal of Evaluation in Clinical Practice, Vol. 16 No. 3, pp. 456-463.

Pines, J.M., Iyer, S., Disbot, M., Hollander, J.E., Shofer, F.S. and Datner, E.M. (2008), "The effect of emergency department crowding on patient satisfaction for admitted patients", Academic Emergency Medicine, Vol. 15 No. 9, pp. 825-831.

QSR International (2012), NVivo Qualitative Data Analysis Software, 10th ed., QSR International, Melbourne.

Ranney, M.L. and Peimer, C.A. (2016), "Online emergency department ratings, patient satisfaction and the age-old issue of communication", BMJ Quality and Safety, Vol. 25, pp. 1-2.

Rashid, W.E.W. and Jusoff, H.K. (2009), "Service quality in health care setting”, International Journal of Health Care Quality Assurance, Vol. 22 No. 5, pp. 471-482.

Rathert, C., Vogus, T.J. and McClelland, L. (2016), "Re-humanizing health care: facilitating 'caring' for patient-centered care", in Ferlie, E., Montgomery, K. and Reff Pedersen, A. (Eds), The Oxford Handbook of Health Care Management, Oxford University Press, Oxford. 
Richardson, J.R., Braitberg, G. and Yeoh, M.J. (2004), "Multidisciplinary assessment at triage: a new way forward”, Emergency Medical Journal, Vol. 16 No. 1, pp. 41-46.

Robert, G. and Cornwell, J. (2013), "Rethinking policy approaches to measuring and improving patient experience", Journal of Health Service Research and Policy, Vol. 18 No. 2, pp. 67-69.

Salisbury, C., Wallace, M. and Montgomery, A. (2010), "Patient experience and satisfaction in primary

Informing quality in emergency

care care: secondary analysis using multilevel modelling”, British Medical Journal, Vol. 341, available at: www.bmj.com/content/341/bmj.c5004.long (accessed 29 July 2017).

Sofaer, S. and Firminger, K. (2005), "Patient perceptions of the quality of health services", Annual Review of Public Health, Vol. 26, pp. 513-559.

Swallmeh, E., Abo-Hamad, W., Gray, J. and Arisha, A. (2014), "Integrating simulation modelling and value stream mapping for leaner capacity planning of an emergency department", The Sixth International Conference on Advances in System Simulation, 12 October.

Watt, D., Wertzler, W. and Brannan, G. (2005), "Patient expectations of emergency department care: phase I - a focus group study", Canadian Journal of Emergency Medicine, Vol. 7 No. 1, pp. 12-16.

Wolf, J., Niederhauser, V., Marshburn, D. and LaVela, S. (2014), "Defining patient experience", Patient Experience Journal, Vol. 1 No. 1, pp. 7-19.

Wong, E.L.Y., Coulter, A., Cheung, A.W.L., Yam, C.H.K., Yeoh, E.K. and Griffiths, S.M. (2012), "Patient experiences with public hospital care: first benchmark survey in Hong Kong", Hong Kong Medical Journal, Vol. 18 No. 5, pp. 371-380.

Yarris, L.M., Frakes, B., Magaret, N., Adams, A.L., Brooks, H. and Norton, R.L. (2012), "How accurately can emergency department providers estimate patient satisfaction?", Western Journal of Emergency Medicine, Vol. 13 No. 4, pp. 351-357.

Zachariasse, J.M., Seiger, N., Rood, P.P.M., Alves, C.F., Freitas, P., Smit, F.J., Roukema, G.R. and Moll, H.A. (2017), "Validity of the Manchester Triage System in emergency care: a prospective observational study", PLoS ONE, Vol. 12 No. 2, p. e0170811, available at: http://journals.plos.org/plosone/article? id=10.1371/journal.pone.0170811 (accessed 3 August 2017).

\section{Corresponding author}

Vivienne Byers can be contacted at: vivienne.byers@dit.ie

For instructions on how to order reprints of this article, please visit our website:

www.emeraldgrouppublishing.com/licensing/reprints.htm

Or contact us for further details: permissions@emeraldinsight.com 